\title{
Assessment of Controls on Pedogenesis and Mineral Nutrients in Agricultural Karst Critical Zones in Guizhou, China and Crete, Greece
}

\author{
A.M. LAWAL ${ }^{1}$, H.L. BUSS ${ }^{1}$ AND P.J. JOHNES ${ }^{2}$ \\ ${ }^{1}$ School of Earth Sciences, University of Bristol, Bristol, \\ UK, BS8 1RJ \\ ${ }^{2}$ School of Geographical Sciences, University of Bristol, \\ Bristol, UK, BS8 1SS
}

The Earth's critical zone (CZ) has been constantly evolving and changing over geological timescales, historically driven by tectonic and climatic forcings. Recently $\mathrm{CZ}$ changes have also been driven by anthropogenic factors occasioned by increases in population, which has increased demand for resources and expansion of agriculture, leading to unsustainable land use practices. As a result, about one-third of global arable lands have been eroded and degraded and they are continually being lost at a rate of about $0.5 \%$ a year. Soils are especially vulnerable to loss and degradation in karst environments where lithology, climate and landscape may contribute to slow formation of nutrient deficient soils. Here we studied soil formation and mineral nutrient production in karst CZs in Guizhou, China and Crete, Greece as functions of land use, slope position, and lithology. The two sites are/were impacted by intensive agriculture but under different timescales and seasonality.

Bulk chemistry of soil and bedrock were analysed by ICP-OES and mineralogy and rock texture by SEM. The results show no clear effect of land use or slope position on mineral elements mass transfer profiles in these soils, but indicated considerable influence of the bedrock composition as well as atmospheric deposition. The bedrock mineralogy and the mass transfer profiles of the mineral elements showed that loss of carbonate minerals leaves the soil matrix enriched with silicate-rich mineral 'impurities' which control soil formation and mineral nutrient content in the soils. Enrichment of some mineral elements $(\mathrm{Ca}, \mathrm{K}$ and $\mathrm{P})$ in the profiles indicated atmospheric deposition and biolifting, a process in which plants scavenge for nutrients and concentrate it in the soil. In Guizhou, China bedrock mineralogy is different from that of Crete, Greece and atmospheric deposition is more prominent in Crete than in Guizhou. We found that small variations in lithology (as some of the minerals found in Guizhou such as mica, pyrite and fluorospar) are absent in Crete) play a dominant role in controlling karst soil mineral nutrient profiles. 